\title{
Complementary/alternative medicine: engulfed by postmodernism, anti-science and regressive thinking
}

Complementary and alternative medicine (CAM) has become an important topic for public health. Its use is on the increase; in the US and Germany, for instance, about two-thirds of the general population now use CAM. ${ }^{1,2}$ Health authorities across the globe now feel the need to deal with the implications of such widespread use. More than half of all WHO member states now have a national office for CAM and $43 \%$ support an expert committee on the subject. $^{3}$ This high level of attention seems justified but must be guided by clear thinking. Worryingly this is often not the case. In this article, I will attempt to clarify the confusions that CAM is often plagued by.

\section{CONFUSIONS}

\section{Postmodernism}

Post-modern ideas have infiltrated CAM. Science's quest for truth is seen as a politically motivated 'struggle for power', in which the 'societal approach is pitted against reductionism' ${ }^{4,5}$ The claim is that 'CAM poses huge challenges not only to the dominance of biomedicine, but also to the fruits of dominance - status and power in decision making about health care and the livelihood of physicians ${ }^{\prime 6}$ or that CAM poses a 'threat ... to the long-standing hegemony of biomedicine in the West'. ${ }^{7}$ In order to fend off this threat, conventional medicine is said to 'attack the medical competition, show no intellectual tolerance, and only take those prisoners, who can be converted'. ${ }^{4}$

\section{Anti-science}

Many enthusiasts of CAM are overtly antiscientific, believing that subjecting CAM to scientific testing misses the point and fails to account for its cultural diversity. Measuring Chinese philosophy with a 'Western' yardstick, for instance, is seen as a travesty to pluralism. ${ }^{8}$ Scientists, it is claimed, do not recognise that their own way of reasoning is not a value-free endeavour but culturally constructed and deeply embedded in larger political structures. ${ }^{9}$ According to this line of thought, fundamental philosophical issues determine which therapy is effective or safe. The 'Western medical system', is only one of several approaches, and not necessarily the best. ${ }^{10}$ In the past, it is argued, conventional medicine repeatedly got it wrong, so why should it be right today?"1 "Biomedically trained experts', it is claimed, 'ignore most of the aspects that advocates of alternative therapies draw on as evidence of therapeutic effectiveness'. They are convinced that 'there is no such a thing as The Evidence, just competing bodies of evidence'?

\section{Double standards}

The scientific method is viewed as too narrow to be able to capture CAM in all its complexity. 8,12,11 'Scientifically constructed evidence for an alternative therapy', CAM enthusiasts argue, 'only works when the therapy has mutated into a medicalised version and divested itself of its alternative philosophy'. 'The narrowness of ... science has become apparent, so full of fact and empty of meaning'. ${ }^{13}$ 'Orthodox medicine should consider abandoning demands that CAM become evidence-based, at least as 'evidence' is currently narrowly defined, but insist instead upon a more complete description and defence of the alternative epistemic methods and tools of these disciplines'.$^{14}$ Evidence-based medicine, it is claimed, is inapplicable to CAM because it does not necessarily represent the dominant or preferred logic of [CAM] practitioners', ${ }^{4}$ and is viewed as 'a new paradigm in orthodox medicine' representing 'a hegemonic cultural movement generated as a continuation of the ascendency of medical dominance'. ${ }^{4}$

\section{Paradigm shift}

A shift to a new paradigm is therefore required: ${ }^{11}$

\section{'... chiropractors begin with a different}

set of assumptions, use different theoretical explanations, embrace a different philosophy, pose different questions and use different language ... than medicine'. ${ }^{15}$

The new 'holistic paradigm' includes 'concepts of psychosomatism, consciousness and energy'. ${ }^{16}$ According to some, the meaning of illness and health is neglected by conventional medicine to its peril: 'sometimes, illness is the patient's best friend'. ${ }^{17}$ The multidimensionality of life, and our existence means that the research tools of science are too limited to generate meaningful insights - 'the round problems of CAM' do not fit 'into the square holes of the scientific method'. ${ }^{18}$ The dilemma, some CAM enthusiasts insist, is "how to prove scientifically something which does not fit the framework of scientific belief'. ${ }^{13}$ For those who only have a hammer (conventional scientists) the world consists only of nails. ${ }^{12}$ Modern medicine is deemed to be in a crisis, and only a shift of paradigms can save us from it. ${ }^{12,11}$

Evidence-based medicine is seen as a 'fashion' obsessed with linear thinking which is 'antithetical' to CAM and ignores 'the wisdom of tradition'. 'A full analysis presents a level of complexity that tends to overwhelm its methodology'. ${ }^{17}$ Whenever conventional clinical trials produce negative results concepts such as: 'quantum theory', 'entanglement', 'chaos theory', and 'fuzzy logic' are quoted to imply that CAM works after all. ${ }^{7,19}$ If this fails, it is argued that 'knowledge from randomised clinical trials would be of little use in therapeutic practice'. ${ }^{4}$

\section{Terminology}

The CAM literature is rife with terminology such as vitalism, energy, balance, toxins and detoxification, and immuneboosting. ${ }^{4,6,8,10,12,15,18,19}$ These words are usually couched in pseudo-scientific language. ${ }^{20}$ For the lay person, such discussions seem to be 
based on scientific facts providing easily understood and superficially plausible explanations for therapeutic approaches. Lay audiences are therefore misled to believe that such terminology signifies good science.

\section{Politics}

Legislative efforts and tax payers' money are currently directed towards regulating CAM professions. But regulation is not primarily an instrument for increasing the credibility of CAM providers, it must foremost ensure the safety of the public. Regulation of nonsense must result in nonsense. Public funds have been spent on publishing a UK patient guide $^{21}$ which avoids addressing efficacy and is instead a promotional booklet for unproven treatments. ${ }^{22}$ A report commissioned by the Prince of Wales to influence UK health policy claims that huge amounts of money could be saved if the NHS adopted CAM treatments routinely. ${ }^{23}$ The report was aimed at politicians, and without expertise in health economics, most of its contents might appear unreasonable. ${ }^{24}$

\section{CLARIFICATIONS}

For over 15 years, I have struggled with this level of confusion, tried to understand what lies behind the misunderstandings and discussed the issues with advocates of CAM. Sadly it seems that the degree of confusion has not significantly decreased. On the contrary, I fear that misunderstandings are sometimes deliberately perpetuated.

Whether homoeopathy (or any other CAM modality) is effective cannot depend on what concept of knowledge we happen to favour. Neither is a "quantum perspective'25 likely to generate a meaningful answer to this question. Clinical effectiveness is a falsifiable hypothesis applicable to all interventions. Those who deny this fact may have reasons for trying to mislead us. The notion that 'Bach Flower Remedies' have healing power is not a political, sociological or philosophical collision. It is a claim that can be tested in rigorous clinical trials. ${ }^{26}$ The notion that CAM is a 'threat to the profits of the drug companies ${ }^{27}$ is unsubstantiated and, to the best of my knowledge, not correct.

Testing the efficacy and safety of CAM is not just an obsession of scientists; it is a concern for the health of individuals and the public at large. Chiropractors posing as primary care providers under the 'new paradigm'15 are not a 'conundrum' but represent a concept the value of which can be scientifically determined. Based on the data available to date, it is impossible to deny that the results are far from convincing. ${ }^{28,29}$ Anatomy, physiology, and pathology are not 'Western medical systems', they are generalisable truths that apply to all humans. To call scientific medicine 'Western' or 'reductionist' is discriminating and reminiscent of calling Einstein's discoveries 'Jewish physics'. ${ }^{30}$ Cancer patients may long for 'practitioners with a different understanding of their disease and treatment, than those offered within the conventional healthcare system' ${ }^{31}$ This language does not render the nurturing of false hopes in vulnerable patients less unethical, and should not distract from the fact that cancer patients foremost want to be cured. A cure requires effective treatments not a 'meaning'. ${ }^{32}$ 'Healing' that fails to heal ${ }^{32}$ is dangerous.

There is no alternative to the scientific method for evaluating the value of medical interventions, even though some may think that 'the science of biomedicine ... [is] perceived as old-fashioned and rejected in favour of the quantum and chaos theories of modern physics'. ${ }^{7}$ Advocating research to investigate the 'phenomenology of the lived body using more creative methodologies to deal with processes, in both the researcher and the researched, such as intuition, somatic perception, bodily imagination and sensation' does not mean anything. ${ }^{33}$ Such anthropological or sociological studies at best inform us about patients' and therapists' 'beliefs about health, illness and the body, and about the nature of the healing process', ${ }^{7}$ they can, however, never tell us which treatments are most effective for which condition.

Cultural diversity of CAM is a reality but, it is no substitute for proof of efficacy and certainly not a 'raison d'ẹtre' in itself. The ritual killing of a child for improving the health of an adult, or enforced female genital mutilation as a means of securing good sexual health might be seen as cultural diversity but they are also cruel and wrong deliberately extreme examples to demonstrate that cultural diversity is not a value in itself or a sound basis for healthcare decisions. ${ }^{34}$
'Whenever a proponent of a controversial empirical claim counters criticisms of the evidence by reference to a 'paradigm shift', it is time to put on one's hip waders. To the extent that 'paradigm' just means a new theoretical view, it prevails because of - not in spite of - sound evidence. The rise of quantum mechanics is frequently referenced as the paradigmatic example of paradigm shift. But the discoverers of quantum mechanics did not have to philosophically argue their opponents into making a paradigm shift before quantum phenomena were accepted. The proponents merely presented everincreasing amounts of solid evidence. To the extent that 'paradigm shift' is used to describe something about the social and historical process of how research is done, it has little legitimate role in discussions of evidential quality. Most other uses are so vague that no significant meaning can be attached'. ${ }^{35}$

Specifically writing about CAM, Andrew Vickers stated that:

'... paradigms might well have a useful conceptual role in some fields of discourse; it has yet to be argued that this is the case in complementary medicine research ... Reference to paradigms leads to crude generalisations rather than useful, detailed analysis ... The paradigm moves from being an explanation for the nature of scientific change, to becoming the 'bogeyman': a packaging of nebulous fears and animosities into a discrete entity which no-one can see but whose existence can be deduced by its effects ... In short, we need to stop talking about paradigms... ${ }^{36}$

Some concepts of CAM can be identified as unhelpful, conservative nostalgia:

'This pseudo medicine with its language of rebalancing, detoxifying, and cleansing is one strand in anti-science conservative sentiment. It thinks modern lifestyles dangerous with toxins and poisons all around us, invisible horrors in the air and water unknown to a purer, better era (time unspecified). We 
are to blame for our diseases because we interfered with nature. The primitive is good, the civilised bad, the past is healthy while the present is sick and the future is terrifying. Conservative nostalgia is at its dottiest on health, trusting to remedies from days when children died in droves, women were ripped apart in labour and no one lived long. ${ }^{37}$

In the realm of CAM, conservatism, regressive thinking and post-modernist opposition to science converge. Holism is a concept that has always been at the core of any good medical practice ${ }^{38}$ It is not a monopoly of CAM. 'The didactic, paternalistic, authoritative, mystifying mantle has passed to the alternative therapist, and to wear it requires one thing most doctors are uncomfortable with, dishonesty' ${ }^{39}$

\section{IMPLICATIONS}

The muddled and regressive thinking criticised above is currently being integrated in medical education, ${ }^{40,41}$ in medical practice $^{8,42}$ and in research capacity development. ${ }^{7}$ A survey of chairpersons of 72 primary care organisations in England showed that $85 \%$ of these organisations had discussed CAM at board level..$^{42}$ The most important driver of CAM policy and provision was 'existing local CAM provision'; evidence of benefit only ranked on third place. A report sponsored by the UK Department of Health National Co-coordinating Centre for Research Capacity Development stated that there are legitimate perspectives on evidence which are 'worlds apart'. ' Are these concepts in danger of converting evidencebased medicine into popularity-based or intuition-based medicine? Currently around 14000 spiritual healers practise in the UK. ${ }^{43}$ A government-sponsored patient guide promotes healing with the words:

\section{'... the laying on of hands ... aims to promote better health by channelling energy through the healer to the patient ... Research has shown some benefits in many areas including healing of wounds, chronic conditions ... reducing side-effects of chemotherapy... ${ }^{21}$}

Yet the best evidence clearly shows that spiritual healing is a placebo therapy ${ }^{44}$ There is, of course, nothing wrong with benefiting from placebo responses - except that all treatments, even those that are effective in the conventional sense, are associated with placebo effects. Do we really need to believe in 'spiritual energies' and violate fundamental rules of medical ethics (that is, telling the truth) in order to profit from placebos?

Faced with a life-threatening diagnosis, some cancer patients turn to CAM 'hoping for a cure or prolonging life by immune system boosting'. ${ }^{45}$ The harsh reality is that misleading patients in this way does not cure cancer, ${ }^{46}$ in fact, it may even shorten their lives $^{47}$ and is certainly unethical. True, 'scientific evidence ranks very low for most patients ${ }^{48}$ but it is time to realise why: it is because we allow our patients to be bombarded with misinformation and do little about it. ${ }^{49}$ If we ignore the evidence when making healthcare decisions, we endanger the health of our patients. And, if it happens on a large scale in a politically-endorsed fashion, the health of the nation will suffer.

A survey of CAM courses offered to healthcare professionals by 25 institutions of higher education in the UK showed that the aims of these courses were often not welldefined, ${ }^{50}$ included themes such as 'holistic study skills', the 'philosophical basis of Chinese medicine', 'heteropathy of Chinese herbal treatment' and 'theory of energy,, ${ }^{1}$ and were devoid of any sign of critical analysis. If the next generation of 'CAM experts' is systematically brainwashed, how are they going to make a meaningful contribution to the future health of the nation?

Muddled thinking in CAM, often comes under the guise of integrated or integrative medicine. ${ }^{9}$ Only very few individuals are courageous enough to speak out against this nonsensical concept. ${ }^{51}$ Those who do are branded as narrow-minded, heartless scientists who know nothing about 'real-life' health care. My team have shown repeatedly that some forms of CAM have considerable potential; in order to apply it to the benefit of patients, the best way forward is that of evidence-based medicine. ${ }^{47,52}$ Creating double-standards and applying muddled thinking may have short-term 'success' but, in the long run, it will be to the detriment of all parties involved, particularly the patient.

\section{Edzard Ernst}

\section{REFERENCES}

1. Barnes PM, Powell-Griner E, McFann K, Nahin RL Complementary and alternative medicine use among adults: United States, 2002. CDC Advance Data Report \#343. May 27, 2004. http://www.cdc.gov/nchs/data/ad/ ad343.pdf (accessed 4 Mar 2009).

2. Härtel U, Volger E. Use and acceptance of classical natural and alternative medicine in Germany - findings of a and alternative medicine in Germany - finding
representative population-based survey. Forsch Komplementarmed Klass Naturheilkd 2004; 11:327-334.

3. World Health Organisation. National policy on traditional medicine and regulation of herbal medicines. Geneva: $\mathrm{WHO}$ 2005.

4. Jagtenberg T, Evans S, Grant A, et al. Evidence-based medicine and naturopathy. J Altern Complement Med 2006; 12: $323-328$

5. Koutouvidis N. CAM and EBM: arguments for convergence. J R Soc Med 2004; 97: 39-40.

6. Ruggie M. Marginal to mainstream. Alternative medicine in America. Cambridge: Cambridge University Press, 2004.

7. Barry CA. The role of evidence in alternative medicine: contrasting biomedical and anthropological approaches. Soc Sci Med 2006; 62: 2646-2657.

8. Giordano J, Garcia MK, Strickland G. Integrating Chinese traditional medicine into a US public health paradigm. $J$ Altern Complement Med 2004; 10: 706-710.

9. Baer $\mathrm{H}$. Toward an integrative medicine: merging alternative therapies with biomedicine. Walnut Creek, CA: Altamira Press, 2004.

10. O'Connor BB. Healing traditions. Alternative medicine and the health professions. Philadelphia: University of Pennsylvania Press, 1995.

11. Hyman M. Paradigm shift: the end of 'normal science' in medicine understanding function in nutrition, health, and disease. Alternative Therapies 2004; 10: 10-15.

12. Walach H. Wider naiven Empirismus und verkleidete Machtansprüche - politische und wissenschaftstheoretische Splitter [Against naive empiricism and power in disguise - political and philosophical ruminations]. Forsch Komplementarmed Klass Naturheilkd 2004; 11: 72-75.

13. Barnard J. Bach Flower Remedies form and fuction. Great Barrington, MA: Lindisfarne Books, 2004.

14. Tonelli MR, Callahan TC. Why alternative medicine cannot be evidence-based. Acad Med 2001; 76: 1213-1220.

15. Coulter ID. The chiropractic paradigm. J Manipulative Physiol Ther 1990; 13:279-287.

16. Tobert N. Research paradigms in CAM [workshop]. Nottingham University: ACHRN Conference, Nottingham, 29 Jun 2005.

17. Werbach MR. Medical science and scientism: when is belief in science a religion? Altern Ther 2004; 10: 14-92.

18. Whitelegg M. Goethean science: an alternative approach. $J$ Altern Complement Med 2003; 9: 311-320.

19. Kenyon J. Integrated medicine bringing back creativity. Cam 2004; Mar: 34-40.

20. Ernst E. Bioresonance, a study of pseudo-scientific language. Forsch Komplementärmed Klass Naturheilkd 2004; 11: 171-173.

21. The Prince of Wales's Foundation for Integrated Health. Complementary healthcare: a guide for patients. London: The Prince of Wales's Foundation for Integrated Health, 2005.

22. Ernst E. Keynote comment: dumbing down of complementary medicine. Lancet Oncol 2005; 6: 442-443.

23. Smallwood C. The role of complementary and alternative medicine in the NHS. An investigation into the potential contribution of mainstream complementary therapies to healthcare in the UK. London: Freshminds, 2005.

24. Ernst E. The 'Smallwood report': method or madness? Br J Gen Pract 2006; 56: 64-65.

25. Milgrom L. Quantum perspective on CAM research [workshop]. ACHRN Conference, Nottingham University, Nottingham, 29 Jun 2005.

26. Ernst E. 'Flower remedies': a systematic review of the clinical evidence. Wien Klin Wochenschr 2002; 114: 963-966.

27. Mastrangelo D, Lore C. The growth of a lie and the end of 'conventional' medicine. Med Sci Monit 2005; 11 SR27-SR31

28. Ernst E. Chiropractic: a critical evaluation.J Pain Symptom Manage 2008; 35: 544-562.

29. Singh S, Ernst E. Trick or treatment? Alternative medicine on trial. London: Bentham, 2008.

30. Atwood KC. A critique of the Annals of Alternative 
Medicine' distant healing review. Scientific Review of Alternative Medicine 2002; 6: 99-101.

31. Steinsbekk A, Launso L. Empowering the cancer patient or controlling the tumor? A qualitative study of how cancer patients experience consultations with complementary and alternative medicine practitioners and physicians, respectively. Integr Cancer Ther 2005; 4: 195-200.

32. McGuire MB. Ritual healing in suburban America. New Brunswick, NJ: Rutgers University Press, 1988

33. Csordas T. Embodiment as a paradigm in anthropology. Ethos 1990; 18: 5-47.

34. Ernst E. Cultural diversity in healthcare. Perfusion 2004; 17: 33

35. Turpin R. Characteristics of pseudoscience. Scientific Review of Alternative Medicine 2002; 6: 102-105.

36. Vickers A. Research paradigms in mainsteam and complementary medicine. In: E Ernst (Ed) Complementary medicine: an objective appraisal. London: Butterworth Heinemann, 1996: pp: 1-17.

37. Toynbee P. Charles is more keeper of the kitsch than heir to the throne. http://politics.guardian.co.uk/columnist/ story/0,9321,1250431,00.html (accessed 4 Mar 2009).
38. Ernst E. Disentangling integrative medicine. Mayo Clin Proc 2004; 79: 565-566.

39. Goldacre B. A tonic for sceptics. http://www.guardian.co. uk/science/2005/aug/29/badscience.health (accessed $4 \mathrm{Mar}$ 2009)

40. Bartecchi CE. 'Alternative' medicine's free ride. Scientific Review of Alternative Medicine 2004; 8: 5-8.

41. Ernst $\mathrm{E}$. Teaching complementary/alternative medicine for primary care. Ed Prim Care 2003; 14: 414-418.

42. Thomas KJ, Coleman P, Weatherley-Jones E, Luff D. Developing integrated CAM services in primary care organisations. Complement Ther Med 2003; 11: 261-267.

43. Mills S, Budd S. Professional organisation of complementary and alternative medicine in the United Kingdom 2000. A second report to the Department of Health. Exeter: Centre for Complementary Health Studies, University of Exeter, 2000.

44. Ernst E. Distant healing — an 'update' of a systematic review. Wien Klin Wochenschr 2003;115:241-245.

45. Evans MA, Shaw A, Sharp DJ, et al. Male cancer patients' views on and use of CAM: a qualitative study. Focus Altern Complement Ther 2004; 9: 12-13.

46. Ernst E, Pittler MH, Stevinson C, White AR. The desktop guide to complementary and alternative medicine. Edinburgh; Mosby, 2001

47. Risberg T, Vickers A, Bremnes RM, et al. Does use of alternative medicine predict survival from cancer? Eur $J$ Cancer 2003; 39: 372-377.

48. Verhoef M, Mulkins A, Oneschuk D, Carlson L. Cancer patients' understanding of evidence. Focus Altern Complement Ther 2004; 9: 56.

49. Goldacre B. Bad science. London: Fourth Estate Ltd, 2008.

50. Ernst E, Schmidt K. Courses in complementary medicine at institutions of higher education in the United Kingdom International Journal of Naturopathic Medicine 2004; 1: $56-69$

51. Ernst E. Healing, hype or harm? A critical analysis of complementary or alternative medicine. Exeter: Societas Imprint Academics, 2008.

52. Ernst E, Pittler M, Wider B, Boddy K. Oxford handbook of complementary medicine. Oxford: Oxford University Press, 2008

DOI: 10.3399/bjgp09X420482

\section{COMMENTARY}

This paper presents legitimate criticism of the nebulous field described as CAM. It has relevance to primary care whose practitioners may encounter the muddled thinking it describes. But it does not tell the whole story. As it stands, its pejorative tone and tendentious quality, even its element of sophistry, undermine its argument. There are CAM researchers and practitioners who bring a proper spirit of scientific enquiry to its exploration; who do not succumb to, indeed deprecate the vagaries described here. Nor are GPs so susceptible to them.

GPs' approach to decision making is eclectic, involving collective experience, tacit knowledge and professional networking, succinctly expressed as 'informed empiricism', (R Pinsent, personal communication, 1980) rather than an exclusively linear-rational model of evidence-based care. ${ }^{1}$ A combination of knowledge, clinical experience and sound judgement ensures they usually get it right. ${ }^{2}$ GPs have a long and positive acquaintance with leading CAM therapies. ${ }^{3}$ They are aware of the shaky evidence base for much conventional practice as well as CAM, and are as capable of applying their 'knowledge in practice' to both. '

Ernst's sometimes limited and selective use of evidence does not help. An example from his book Trick or Treatment is the risk of stroke incorrectly attributed to chiropractic manipulation of the cervical spine. ${ }^{5,6}$ Whereas the impressive level of benefit reported in the Bristol Homeopathic Hospital clinical outcome study, discounted by Ernst for lack of controls, will signify effectiveness to the discerning GP, whatever its limits as a demonstration of efficacy. ${ }^{7,4}$

A regrettable consequence of Ernst's polemic is to polarise attitudes to CAM when rapprochement would be more fruitful. At its worst, it encourages clinicians to denigrate CAM to patients expressing interest, compromising the therapeutic relationship and perhaps prompting them to become conventional medicine 'abandoners' (G Lewith, personal communication, 2009).

This unbalanced presentation of the CAM debate distracts from the exploration of what can be learned from unorthodox approaches (placebo or otherwise), that enable self-regulation and enhance wellbeing, truly complementing the achievements of orthodox methods. I have contributed to Vickers's critique of $\mathrm{CAM},{ }^{8}$ but the paradigm problem he dismisses in Ernst's quotation undoubtedly has practical consequences. ${ }^{9}$ The type of revolution that Kuhn described when he introduced the concept, a metanoia, really is needed if medicine is to evolve, rather than merely advance on the same narrow front. ${ }^{10}$ As David Haslam wrote, 'We use the medical model because the medical model is what we use, even though it may not always be appropriate."11

\section{Jeremy Swayne}

\section{REFERENCES}

1. Gabbay J, le May A. Evidence based guidelines or collectively constructed 'mindlines'? Ethnographic study of knowledge management in primary care. BMJ 2004; 329(7473):1013.

2. Harnden A, Lehman R. New primary care series: Easily Missed. BMJ 2009; 338: b491.

3. Wharton R, Lewith G. Complementary medicine and the general practitioner. BMJ 1986; 292:1498-1500.

4. Ernst E, Singh S. Trick or treatment: alternative medicine on trial. London: Bantam Press, 2008.

5. Thiel HW, Bolton JE, Docherty S, Portlock JC. Safety of chiropractic manipulation of the cervical spine: a prospective national survey. SPINE 2007, 32(21): $2375-2378$.

6. Cassidy JD, Boyle E, Côté P, et al. Risk of vertebrobasilar stroke and chiropractic care. Eur Spine J 2008, 17(Suppl 1): S176-S183.

7. Spence DS, Thompson EA, Barron SJ. Homeopathic treatment for chronic disease: a 6-year, university hospital outpatient observational study. J Altern Complement Med 2005; 11(5): 793-798

8. Swayne J. Homeopathic therapeutics: many dimensions — or meaningless diversity? In: Vickers A (ed.). Examining complementary medicine: the sceptical holist. Cheltenham Stanley Thornes, 2002.

9. Swayne J. Truth, proof and evidence: homeopathy and the medical paradigm. Homeopathy 2008, 97: 89-95

10. Kuhn, T. The structure of scientific revolutions. Chicago: University of Chicago Press, 1996.

11. Haslam D. Who cares? Br J Gen Pract 2007; 57(545): 987-993.

DOI: 10.3399/bjgp09X420491 